3-1-2006

\title{
The Time Course of Variability Effects in the Perception of Spoken Language: Changes Across the Lifespan
}

Conor T. McLennan

Cleveland State University, c.mclennan@csuohio.edu

Follow this and additional works at: https://engagedscholarship.csuohio.edu/clpsych_facpub

Part of the Speech and Hearing Science Commons

How does access to this work benefit you? Let us know!

Publisher's Statement

(c) 2006 SAGE Publications

\section{Recommended Citation}

McLennan, C. (2006). The time course of variability effects in the perception of spoken language: changes across the lifespan. Language \& Speech, 49(Part 1), 113-125.

This Article is brought to you for free and open access by the Psychology Department at EngagedScholarship@CSU. It has been accepted for inclusion in Psychology Faculty Publications by an authorized administrator of EngagedScholarship@CSU. For more information, please contact library.es@csuohio.edu. 


\section{The Time Course of Variability Effects in the Perception of Spoken Language: Changes Across the Lifespan}

\section{Conor T. McLennan}

University at Buffalo, The State University of New York

\section{Key words}

Adaptive

Resonance

Theory [ART]

framework

language

perception

talker effects

variability

\begin{abstract}
Although spoken language is communicated via a rapidly varying signal, human listeners recognize spoken words both quickly and accurately. Nonetheless, variability in speech does have implications for both the processes and representations involved in spoken language perception. Moreover, variability effects have been observed across the lifespan, ranging from infants to older adults. Many factors could potentially modulate the degree to which variability affects spoken language perception. In particular, recent findings demonstrate that variability effects follow a time course, manifesting themselves at predictable points during perceptual processing. However, time course investigations are currently limited to young adults. Therefore, the current paper explores how the time course of variability effects might differ throughout the lifespan, based on predictions derived from an adaptive resonance framework.
\end{abstract}

\section{Introduction}

Although spoken language is communicated via a rapidly varying signal, human listeners recognize spoken words both quickly and accurately. Nonetheless, the results from decades of research demonstrate that variability in the signal (e.g., due to differences in talker and/or speaking rate) has implications for both the processes and representations involved in spoken language perception. Although there are many different types of variability, the majority of the research on variability effects has focused on talker variability (Nusbaum \& Magnuson, 1997; Pisoni, 1997). Consequently, the focus in the current paper will be on talker variability effects, one particular type of indexical variability. Indexical variability refers to variations in a 
spoken word that arise from differences among talkers, speaking rates, affective states, and so on (Abercrombie, 1967; Pisoni, 1997).

Research studies on variability effects have been carried out in a variety of populations, including infants (Houston \& Jusczyk, 2003), preschool children (Ryalls \& Pisoni, 1997), young adults (Palmeri, Goldinger, \& Pisoni, 1993), older adults (Sommers, 1996), hearing impaired (Kirk, Pisoni, \& Miyamoto, 1997), and patients with Alzheimer's Dementia (Sommers, 1998). Furthermore, previous research is not entirely limited to talker variability effects. For example, speaking rate variability effects have also been examined in infants (Eimas \& Miller, 1980; Miller \& Eimas, 1983), young adults (Nygaard, Sommers, \& Pisoni, 1995), and older adults (Sommers, 1997).

Many factors could potentially modulate the degree to which variability affects spoken language perception. In particular, recent findings demonstrate that variability effects follow a time course, manifesting themselves at predictable points during perceptual processing (McLennan \& Luce, 2005; McLennan, Luce, \& CharlesLuce, 2003). However, time course investigations are currently limited to young adults. Therefore, the goal of the current paper is to explore how the time course of variability effects might differ throughout the lifespan, in particular in infants and older adults.

\section{Previous research on variabilitity effects}

\section{1}

\section{Young adults}

Much of the research on variability effects has been carried out with young adults and has focused on the processing and representational implications of talker variability. The processing work demonstrates that spoken language perception is both slower and less accurate when particular aspects of the spoken input, such as the identity of the talker, vary throughout the course of an experiment. Two of the earliest research studies to investigate processing costs due to talker variability were carried out by Peters (1955) and Creelman (1957). Peters found that single-talker messages were reliably more intelligible than multiple-talker messages when embedded in noise. Creelman obtained a similar pattern of results. He found an inverse relationship between spoken word identification performance and number of talkers: As the number of talkers increased, young adults' identification performance decreased. These early studies demonstrate that although human listeners apparently deal with variability in speech remarkably well, it can in fact result in processing costs.

Later work investigated the relationship between talker variability and the perception of isolated words. For example, Mullennix, Pisoni, and Martin (1989) found that identification performance for blocks of familiar English spoken words was more accurate in single-talker than in multiple-talker conditions. These researchers also obtained a reaction time (RT) effect, with faster RTs to repeat words from single-talker lists compared to multiple-talker lists ${ }^{1}$. A number of other studies have obtained similar results, demonstrating performance costs (measured in terms of decreased

1 This RT effect has been replicated with both fewer items and talkers (McLennan, 2003). 
accuracy, increased reaction times, or both) associated with processing words spoken by multiple talkers, relative to a single talker (see Pisoni, 1990; 1992).

The representational work demonstrates that surface details associated with variability (again, in particular, talker-identity) are represented in memory and can affect subsequent perception. Schacter and Church (1992; see also Church \& Schacter, 1994) found that participants' performance on a stem-completion task was significantly improved when the words were spoken by the same talker as an initial exposure phase. Palmeri, Goldinger, and Pisoni (1990) obtained a similar result. These authors found that recognition accuracy decreased if a word was repeated in a different voice than if it was repeated in the same voice. A number of other studies have obtained similar results (see e.g., Bradlow, Nygaard, \& Pisoni, 1999; Craik \& Kirsner, 1974; Goldinger, 1996; Martin, Mullennix, Pisoni, \& Sommers, 1989).

\section{2}

\section{Infants}

Although the majority of the work on variability effects in spoken language perception has focused on young adults, this issue has also been investigated with infants. Kuhl $(1979 ; 1983)$ was the first to systematically investigate the effects of talker variability in infants' perception of speech. She found that six month-olds could discriminate vowel contrasts across different talkers. Furthermore, work by Jusczyk, Pisoni, and Mullennix (1992) revealed that even at as young as two-months of age, infants are able to detect syllable changes produced by different talkers. These findings demonstrate that infants are able to cope with talker variability in their perception of spoken language (see also, Miller, Younger, \& Morse, 1982).

More recent work reveals that processing costs associated with talker variability are not limited to young adults but exist in infants as well. Houston and Jusczyk (2000) examined 7.5 and 10.5 month-old infants' abilities to recognize spoken words in the presence of talker changes. They familiarized both groups of infants with words produced by one talker and later exposed the infants to words spoken by a different talker, either of the same or different gender. They obtained significant variability effects in the 7.5 month-old infants. When the gender of the talkers differed, only the 10.5 month-olds showed recognition of the familiarized words.

Jusczyk, Hohne, Jusczyk, and Redanz (1993) conducted one of the first studies to investigate the long-term consequences of variability in infants' perception of spoken language. Two weeks after familiarizing 8.5 month-old infants with spoken stories, these authors presented the infants with lists of words, either spoken by the same talker as the original familiarization phase or by a different talker. They found that infants listened significantly longer to lists produced by the same talker, suggesting that infants' memory of spoken lists of words includes the indexical information associated with talker identity. More recently, Houston and Jusczyk (2003) investigated infants' long-term memory for the linguistic and indexical properties of individual spoken words (rather than for complete lists of words). As in the earlier Jusczyk et al. study with lists of words, Houston and Jusczyk found that indexical variability played a significant role in the infants' ability to access words from long-term memory. 


\section{3 \\ Older adults}

In addition to infants and young adults, variability effects have been obtained in older adults. In fact, Sommers $(1996 ; 1997)$ has demonstrated that older adults exhibit greater processing costs associated with talker variability than younger adults. $\mathrm{He}$ found that although both younger and older adults were less accurate at identifying spoken words in multiple-talker conditions than in single-talker conditions, the effect was greater for older adults.

In addition to processing costs, long-term representational implications of talker variability have been observed in older adults as well. In fact, several studies have found that older adults are sensitive to the perceptual characteristics of the original episode. Sommers (1999) observed that, like young adults, older adults are sensitive to talker variability between study and test (see also, Yonan \& Sommers, 2000). Furthermore, Naveh-Benjamin and Craik (1995) found that older adults actually benefited slightly more than young adults on recognition memory tests when indexical information, such as the identity of the talker, matched at study and test. Although some studies (e.g., Schacter, Church, \& Osowiecki, 1994) have failed to obtain variability effects in older adults, this may be due to experimental factors (see; Pilotti \& Beyer, 2002; Pilotti, Meade, \& Gallo, 2003; Sommers, 1999).

\section{Time course findings and the adaptive resonance framework}

Recent studies with young adults suggest that variability effects follow a time course, manifesting themselves at predictable points during perceptual processing. Interest in the time course of variability effects originated, in part, from work on allophonic variability. Allophonic variability refers to articulatory and acoustic differences among speech sounds belonging to the same phonemic category (Ladefoged, 2000).

McLennan, Luce, and Charles-Luce (2003) investigated the representational status of flaps - neutralized allophones of intervocalic/t/s and /d/s (see also, Connine, 2004). In casually produced American English, when a / t/ or a /d/ is produced between two vowels, as in rater, it is most frequently realized as a flap, a segment that is neither exactly a /t/ nor exactly a /d/ (Fox \& Terbeek, 1977; see also, Charles-Luce, 1997; Patterson \& Connine, 2001). McLennan et al. conducted a series of experiments in which participants' processing of spoken words was sped or slowed and the productions of the medial segments (flaps or clear $/ \mathrm{t} / \mathrm{s}$ and $/ \mathrm{d} / \mathrm{s}$ ) either matched or mismatched an earlier presentation. They obtained relatively small effects of allophonic variability (mismatch) when processing was slow and more robust effects when processing was fast. McLennan et al. proposed an account of the time course of allophonic variability effects in the context of Grossberg's adaptive resonance theory (ART) framework (Grossberg, 1986; Grossberg \& Myers, 2000; Grossberg \& Stone, 1986).

According to the ART framework, acoustic-phonetic input activates chunks of features corresponding to sublexical and lexical representations. A chunk is a learned set of associated acoustic-phonetic features that may vary in frequency and size; a given chunk may correspond to an individual feature, an allophone, or a word. Chunks 
resonate with the input, with the resonance between input and chunk constituting the percept. Furthermore, more frequent features and combinations of features (i.e., chunks) in a pattern establish resonance with the input more easily and more quickly than less frequent features.

This framework accounts for the time course of allophonic variability effects found in flapping. The more frequent allophonic information (the flap) establishes a resonance with the input more quickly than the less frequent underlying $/ \mathrm{t} / \mathrm{s}$ and $/ \mathrm{d} / \mathrm{s}$. This interpretation led to new predictions for the time-course effects of indexical variability.

Roughly, traditional linguistically based (e.g., phonetic/phonological) features are abstract, whereas features capturing indexical variability (e.g., talker-identity) are less so. Typically, more abstract and general features are higher in frequency, whereas more specific features are lower in frequency. As a result, abstract linguistic features should initially resonate with the input and features capturing indexical information should only resonate with the input after some delay. Consequently, variability effects associated with indexical information, such as talker-identity, should be reduced when processing is fast and more pronounced when processing is slow.

The results of two separate studies are consistent with this prediction. Variability effects were obtained for stimuli that are processed relatively slowly — in particular, lower frequency bisyllabic words (McLennan, Luce, \& Charles-Luce, 2003) but not for stimuli that are responded to more quickly - higher frequency monosyllabic words (Luce \& Lyons, 1998). More recent work directly evaluated the time-course predictions for indexical variability effects. In particular, McLennan and Luce (2005; see also, McLennan, 2003) conducted a series of experiments in which participants' processing of spoken words was sped or slowed. Speed of processing was manipulated in two different ways. First, following from earlier work on allophonic variability (McLennan, Luce, \& Charles-Luce, 2003), the word-likeness of the nonwords present in their lexical decision experiments was manipulated. In the easy discrimination lexical decision experiment, the nonwords were unword-like, allowing for an easy discrimination between the real words and the nonwords in the experiment, which resulted in relatively fast processing. On the other hand, in the difficult discrimination lexical decision experiment, the nonwords were word-like, which resulted in relatively slow processing. Second, the response format in a shadowing task was manipulated. The response format was either the traditional speeded-response or a delayed-response (see Balota \& Chumbley, 1985). In the delayed-response shadowing experiment, participants were instructed to delay their shadowing response until a response cue appeared on the computer monitor. Consistent with the time-course predictions, indexical variability effects were attenuated when processing was fast (easy discrimination lexical decision and speeded-shadowing), relative to when processing was slow (difficult discrimination lexical decision and delayed-shadowing).

\section{Novel time course predictions}

The account based on the adaptive resonance framework also leads to predictions for the time course of variability effects in infants and older adults. Moreover, these 
time course predictions are specific and testable. The adaptive resonance framework, although argued to account for the time course effects, is independent of the more direct and falsifiable hypotheses under discussion.

\section{1}

\section{Infants}

Although it is clear that the ability to focus on more linguistically relevant information (e.g., phonetic distinctions) in the face of variability exists even at a very young age (e.g., Jusczyk, Pisoni, \& Mullennix, 1992; Kuhl, 1979), the time course of processing linguistic and indexical information in infants remains unresolved. Recall that according to the adaptive resonance framework, the difference in frequency between the features corresponding to linguistic and indexical information (with the former typically being more general and thus more frequent than the latter) accounts for the time course effects obtained in young adults. Thus, it follows from this account that indexical information should only come into play later during perceptual processing than linguistic information when there is a sufficient frequency difference between the features corresponding to these two types of information. In particular, the time course effect should only be obtained when the linguistic information has a sufficient frequency advantage over the indexical information. This is unlikely to be the case in the early stages of lexical development. Unlike in young adults, the frequency of the features capturing indexical and linguistic information should be similar in infants. Actually, it is possible that for very young infants, some sources of indexical information are more frequent than linguistic information. For example, newborns may be more sensitive to the indexical information associated with their mothers' voice than with linguistic information. Indeed, newborn infants are able to distinguish their mother's voice from another female's voice (de Casper \& Fifer, 1980). As a result, the features capturing indexical information should establish a resonance (at least) as quickly as the features corresponding to linguistic information. Consequently, the prediction for infants is that indexical variability effects should be obtained at the earliest points during the perceptual processing of linguistic information.

This framework also has implications for the role that variability plays in the development of the lexicon. In particular, it suggests that more abstract linguistic information will come to dominate the early stages of perceptual processing of spoken language as soon as it has a sufficient frequency advantage over more specific indexical information. Because this frequency difference presumably emerges throughout the course of lexical development, variability effects should come into play earlier, and thus exhibit greater effects, in younger infants than in older infants. Recall that Houston and Jusczyk (2000) found that 7.5 month-old infants were more affected by talker (and gender) changes than 10.5 month-old infants, consistent with the interpretation that variability effects come into play earlier, and thus play a larger role, at earlier points during lexical development. Ryalls and Pisoni (1997) obtained a similar pattern of results with preschool children of different ages. They found greater variability effects in younger preschool children than in older preschool children.

The point during development at which linguistic information achieves a sufficient frequency advantage over indexical information to dominate early processing on 
a consistent basis is unclear. However, the degree of variability in the child's environment is one factor that could potentially contribute to how quickly this frequency difference emerges. A sufficient frequency difference between the more irrelevant indexical information and the more important linguistic information (crucial for lexical discrimination) is likely to emerge more quickly in more highly variable environments $^{2}$. More specifically, exposure to variable speech input contributes to the emergence of robust generalized representations. According to Houston and Jusczyk (2000), "The amount of indexical variability in the infant's environment would thus play a large role in developing a mental lexicon" (p.1572). In short, variability could potentially facilitate the process of language acquisition.

\section{2 \\ Older adults}

At least two predictions can be generated for the time course of variability effects in older adults. A hypothesis based on general cognitive slowing (Salthouse, 1985) and age-related reductions in processing speed (Myerson, Ferraro, Hale, \& Lima, 1992) might predict the same time course pattern of indexical variability effects for older adults as that which was observed for young adults. In other words, although older adults are likely to process spoken language more slowly than young adults, the higher frequency features (which typically correspond to abstract linguistic information) should still resonate with the input more quickly than the lower frequency features (which typically correspond to indexical information). Therefore, indexical variability effects should still be relatively small when processing is sped and more robust when processing is delayed. In fact, because the frequency difference (between indexical and linguistic information) is potentially even more exaggerated in older adults than it is in young adults, a more pronounced time course could be predicted for older adults, such that linguistic information resonates with the input early during perceptual processing and the indexical information only resonates after a substantial delay.

An alternative hypothesis for older adults is that their slower processing will simply attenuate the feature frequency difference, such that the additional processing time will allow the resonances between the input and the indexical information to develop and thus time for the indexical information to influence processing. According to this interpretation, indexical variability effects are predicted any time processing is sufficiently slow (as occurs in young adults when processing is slowed) and thus will be observed in older adults even when their processing is sped (because presumably it is still sufficiently slow). This hypothesis assumes that in older adults, indexical and linguistic features will establish resonances with the input at the same point during perceptual processing. Note the same prediction was made for infants. However, in the case of infants, this prediction is based on a lack of a frequency

2 This may be true not only for infants learning their first language but also for adults learning a second language (Barcroft \& Sommers, 2005; see also, Bradlow, Pisoni, Yamada, \& Tohkura, 1997). Also, one of the many reasons immersion techniques may be so successful in foreign language acquisition is that they typically put the language learner in a highly variable environment (e.g., as opposed to being exposed to a relatively limited number of instructors). 
difference between indexical and linguistic features and is therefore temporary. Once a sufficient frequency difference emerges, the resonances are expected to develop at different points and indexical and linguistic information should influence perception at different points during processing. In the case of older adults, this prediction is based on slower processing of spoken language and is thus predicted to be an enduring feature of the aging processing system.

If indexical information associated with variability influences perception at the same point during perceptual processing as linguistic information in older adults, then variability might be expected play a larger role in the perception of spoken language for older adults than for younger adults. Indeed, the results of many studies are consistent with this interpretation (e.g., Naveh-Benjamin \& Craik, 1995; Sommers, 1996; 1997; 1999).

Sommers (1997) has suggested that greater variability effects in older adults could be due to a reduction in perceptual normalization capacities. According to the resonance framework account, indexical information is simply playing less of a role in young adults' perception of spoken language because, unlike older adults, young adults typically process linguistic information before indexical information has had a chance to resonate with the input. Sommers has also suggested that older listeners may be unable to ignore variations in phonetically irrelevant stimulus dimensions as a result of age-related breakdowns in the ability to ignore irrelevant stimulus attributes, despite relatively normal automatic processing (Hasher \& Zacks, 1984). According to the resonance framework account, older adults may have greater difficulty ignoring irrelevant variations in indexical information because the features capturing indexical information resonate with the input at the same point during perceptual processing as the features corresponding to the more important linguistic information.

\section{Concluding remarks}

The ART framework has proven useful both in accounting for the time course results of variability effects with young adults and in generating new predictions for infants and older adults. Furthermore, ART can also account for other findings in the literature and is not limited to a model of variability effects. For example, Vitevitch and Luce (1999) obtained evidence for two distinct levels of representation involved in the processing of spoken words, a sublexical level and a lexical level, each having different consequences for processing (see also, Vitevitch \& Luce, 1998). These authors accounted for their findings within the context of the ART framework. The fact that this simple framework accounts for a wide range of effects, without the need for modifications or additional assumptions, makes it an appealing theory of representation and process.

In discussions of this framework, both in the current paper and elsewhere (see e.g., Luce, McLennan, \& Charles-Luce, 2003; McLennan \& Luce, 2005), representations capturing indexical information have been referred to in terms of features. However, more work is necessary in order to determine more precisely the nature of these representations. Although linguistic information (e.g., phonemes) in the ART 
model is represented in terms of acoustic-phonetic features, it remains unclear exactly how indexical information, such as talker-identity, should be represented.

The ART framework account of the time course of indexical variability effects is consistent with the idea that indexical and linguistic information are qualitatively different and potentially represented in distinct areas of the brain (see e.g., Kreiman \& van Lancker, 1988; van Lancker, Kreiman, \& Cummings, 1989; Marsolek, 1999). Also, whereas linguistic information presumably maps onto discrete representations, indexical information could potentially be represented in a more continuous manner (see e.g., Ryan, Chasaide, \& Gobl, 2003). However, a qualitative distinction between indexical and linguistic information is not a requirement of this framework. Indeed, this framework posits that both indexical and linguistic properties of speech map onto aspects (features?) of the chunks representing lexical information. Consequently, this account is also consistent with claims that indexical and linguistic properties of speech are fundamentally linked (Remez, Fellowes, \& Rubin, 1997).

Overall, the ART framework account for the time course of indexical variability effects can be characterized as follows. Some aspects of the chunks representing lexical information are more general and thus more frequent and other aspects are more specific and less frequent. Furthermore, the more frequent aspects should establish a resonance with the input more quickly than the less frequent aspects. Finally, the more frequent aspects typically correspond to abstract linguistic information and the less frequent aspects typically correspond to more specific paralinguistic information, including indexical information ${ }^{3}$ (again, however, there are exceptions, such as in infants).

Luce and McLennan (2005) recently discussed the challenge that variability poses for current models of spoken word recognition. Despite this challenge, with appropriate modifications other models could potentially account for variability effects. For example, Jusczyk's word recognition and phonetic structure acquisition (WRAPSA) model $(1993,1997)$ accounts for the difference in processing indexical and linguistic information as the lexicon develops.

WRAPSA assumes that infants' lexical representations include indexical information, such as talker-specific details, rather than consisting solely of abstract phonetic descriptions. According to the WRAPSA model, throughout the course of development infants assign greater weight to the properties of speech that are most relevant for making meaningful distinctions. The adjustments in weight to the various properties of the input could be based, at least in part, on the frequency with which they occur. Indeed, there is evidence that infants are sensitive to the regularity with which patterns in the speech stream occur (see e.g., Jusczyk, Luce, \& Charles-Luce, 1994). Therefore, the WRAPSA model could potentially account for the predicted differences in the effects of variability between infants and young adults. Nonetheless,

3 If the different aspects of the chunks consistently establish resonances with the input at different rates, qualitative differences, such as being represented in distinct brain regions, could eventually emerge. For example, information that is more common across a variety of situations may be consolidated into the neocortex more quickly than information that is more variable (McClelland, McNaughton, \& O'Reilly, 1995) 
future work is necessary to determine whether episodic models such as WRAPSA are able to account for the time course of variability effects and the hypothesized different time courses in infants, young adults, and older adults.

An important goal for future research is to develop more fully a theoretical model of spoken language perception that will account for the coexistence of both abstract and more specific representations and for the role that variability plays in infants, young adults, and older adults during the time course of processing spoken language. Regardless of whether an adaptive resonance framework or some alternative framework is ultimately the most successful in accounting for variability effects, future empirical investigations should shed new light on the role that variability plays in the perception of spoken language as processing unfolds over time and how time course effects might change throughout the lifespan.

\section{References}

ABERCROMBIE, D. (1967). Elements of general phonetics. Chicago: Aldine.

BALOTA, D. A., \& CHUMBLEY, J. I. (1985). The locus of word-frequency effects in the pronunciation task: Lexical access and/or production? Journal of Memory and Language, 24, 89-106.

BARCROFT, J., \& SOMMERS, M. S. (2005). Effects of acoustic variability on second language vocabulary learning. Studies in Second Language Acquisition, 27, 387-414.

BRADLOW, A. R., NYGAARD, L. C., \& PISONI, D. B. (1999). Effects of talker, rate, and amplitude variation on recognition memory for spoken words. Perception and Psychophysics, 61, 206-219.

BRADLOW, A. R., PISONI, D. B., YAMADA, R., \& TOHKURA, Y. (1997). Training Japanese listeners to identify English /r/ and /1/: IV. Some effects of perceptual learning on speech production. Journal of the Acoustical Society of America, 101, 2299-2310.

CHARLES-LUCE, J. (1997). Cognitive factors involved in preserving a phonemic contrast. Language and Speech, 40, 229-248.

CHURCH, B. A., \& SCHACTER, D. L. (1994). Perceptual specificity of auditory priming: Implicit memory for voice intonation and fundamental frequency. Journal of Experimental Psychology: Learning, Memory, and Cognition, 20, 521-533.

CONNINE, C. M. (2004). It's not what you hear but how often you hear it: On the neglected role of phonological variant frequency in auditory word recognition. Psychonomic Bulletin and Review, 11, 1084-1089.

CRAIK, F. M., \& KIRSNER, K. (1974). The effect of speaker's voice on word recognition. Quarterly Journal of Experimental Psychology, 26, 274-284.

CREELMAN, C. D. (1957). The case of unknown talker. Journal of the Acoustical Society of America, 29, 655.

De CASPER, A. J., \& FIFER, W. P. (1980). Of human bonding: Newborns prefer their mother's voices. Science, 208, 1174-1176.

EIMAS, P. D., \& MILLER, J. L. (1980). Contextual effects in infant speech perception. Science, 209, $1140-1141$.

FOX, R. A., \& TERBEEK, D. (1977). Dental flaps, vowel duration and rule ordering in American English. Journal of Phonetics, 5, 27-34.

GOLDINGER, S. D. (1996). Words and voices: Episodic traces in spoken word identification and recognition memory. Journal of Experimental Psychology: Learning, Memory, and Cognition, 22, 1166-1183. 
GROSSBERG, S. (1986). The adaptive self-organization of serial order in behavior: Speech, language, and motor control. In E. C. Schwab \& H. C. Nusbaum (Eds.), Pattern recognition by humans and machines: Vol. 1. Speech perception (pp.187-294). New York: Academic Press.

GROSSBERG, S., \& MYERS, C. W. (2000). The resonant dynamics of speech perception: Interword integration and duration-dependent backward effects. Psychological Review, 107, 735-767.

GROSSBERG, S., \& STONE, G. (1986). Neural dynamics of word recognition and recall: Attentional priming, learning, and resonance. Psychological Review, 93, 46-74.

HASHER, L., \& ZACKS, R. T. (1984). Automatic processing of fundamental information: The case of frequency of occurrence. American Psychologist, 39, 1372-1388.

HOUSTON, D. M., \& JUSCZYK, P. W. (2000). The role of talker-specific information in word segmentation by infants. Journal of Experimental Psychology: Human Perception and Performance, 26, 1570-1582.

HOUSTON, D. M., \& JUSCZYK, P. W. (2003). Infants' long-term memory for the sound patterns of words and voices. Journal of Experimental Psychology: Human Perception and Performance, 29, $1143-1154$.

JUSCZYK, P. W. (1993). From general to language-specific capacities: The WRAPSA model of how speech perception develops. Journal of Phonetics, 21, 3-28.

JUSCZYK, P. W. (1997). The discovery of spoken language. Cambridge, MA: MIT Press.

JUSCZYK, P. W., HOHNE, E. A., JUSCZYK, A. M., \& REDANZ, N. J. (1993). Do infants remember voices? Journal of the Acoustical Society of America, 93, 2373.

JUSCZYK, P. W., LUCE, P. A., \& CHARLES-LUCE, J. (1994). Infants' sensitivity to phonotactic patterns in the native language. Journal of Memory and Language, 33, 630-645.

JUSCZYK, P. W., PISONI, D. B., \& MULLENNIX, J. (1992). Some consequences of stimulus variability on speech processing by 2-month-old infants. Cognition, 43, 253-291.

KIRK, K. I., PISONI, D. B., \& MIYAMOTO, R. C. (1997). Effects of stimulus variability on speech perception in listeners with hearing impairment. Journal of Speech, Language, and Hearing Research, 40, 1395-1405.

KREIMAN, J., \& van LANCKER, D. (1988). Hemispheric specialization for voice recognition: Evidence from dichotic listening. Brain and Language, 34, 246-252.

KUHL, P. K. (1979). Speech perception in early infancy: Perceptual constancy for spectrally dissimilar vowel categories. Journal of the Acoustical Society of America, 66, 1668-1679.

KUHL, P. K. (1983). Perception of auditory equivalence classes for speech in early infancy. Infant Behavior and Development, 6, 263-285.

LADEFOGED, P. (2000). A course in phonetics ( $5^{\text {th }}$ ed.). San Diego: Harcourt, Brace, and Jovanovich.

LUCE, P. A., \& LYONS, E. A. (1998). Specificity of memory representations for spoken words. Memory \& Cognition, 26, 708-715.

LUCE, P. A., \& McLENNAN, C. T. (2005). Spoken word recognition: The challenge of variation. In D. B. Pisoni \& R. E. Remez (Eds.), Handbook of Speech Perception, pp. 591-609. Malden, MA: Blackwell.

LUCE, P. A., McLENNAN, C. T., \& CHARLES-LUCE, J. (2003). Abstractness and specificity in spoken word recognition: Indexical and allophonic variability in long-term repetition priming. In J. Bowers \& C. Marsolek, (Eds.), Rethinking implicit memory (pp. 197-214). Oxford: Oxford University Press.

MARSOLEK, C. J. (1999). Dissociable neural subsystems underlie abstract and specific object recognition. Psychological Science, 10, 111-118.

MARTIN, C. S., MULLENNIX, J. W., PISONI, D. B., \& SOMMERS, W. V. (1989). Effects of talker variability on recall of spoken word lists. Journal of Experimental Psychology: Learning, Memory, and Cognition, 15, 676-684. 
McClELlAND, J. L., McNAUGHTON, B. L., \& O'REILlY, R. C. (1995). Why there are complementary learning systems in the hippocampus and neocortex: Insights from the successes and failures of connectionist models of learning and memory. Psychological Review, 102, 419-457.

McLENNAN, C. T. (2003). The time course of indexical specificity effects in spoken word recognition. Dissertation Abstracts International, 64(8), 4078.

McLENNAN, C. T., \& LUCE, P. A. (2005). Examining the time course of indexical specificity effects in spoken word recognition. Journal of Experimental Psychology: Learning, Memory, and Cognition, 31, 306-321.

McLENNAN, C. T., LUCE, P. A., \& CHARLES-LUCE, J. (2003). Representation of lexical form. Journal of Experimental Psychology: Learning, Memory, and Cognition, 29, 539-553.

MILLER, J. L., \& EIMAS, P. D. (1983). Studies on the categorization of speech by infants. Cognition, 13, 135-165.

MILLER, C. L., YOUNGER, B. A., \& MORSE, P. A. (1982). Categorization of male and female voices in infancy. Infant Behavior and Development, 5, 143-159.

MULLENNIX, J. W., PISONI, D. B., \& MARTIN, C. S. (1989). Some effects of talker variability on spoken word recognition. Journal of the Acoustical Society of America, 85, 365-378.

MYERSON, J., FERRARO, F. R., HALE, S., \& LIMA, S. D. (1992). General slowing in semantic priming and word recognition. Psychology and Aging, 7, 257-270.

NAVEH-BENJAMIN, M., \& CRAIK, F. I. M. (1995). Memory for context and its use in item memory: Comparisons of younger and older persons. Psychology and Aging, 10, $284-293$.

NUSBAUM, H., \& MAGNUSON, J. (1997). Talker normalization: Phonetic constancy as a cognitive process. In K. Johnson \& J. W. Mullennix (Eds.), Talker variability in speech processing (pp. 109-132). San Diego, CA: Academic Press.

NYGAARD, L. C., SOMMERS, M. S., \& PISONI, D. B. (1995). Effects of stimulus variability on perception and representation of spoken words in memory. Perception and Psychophysics, 57, 989-1001.

PALMERI, T. J., GOLDINGER, S. D., \& PISONI, D. B. (1990). Effects of talker variability on recognition memory for spoken words. Research on Speech Perception Progress Report, 16. Bloomington, IN: Indiana University.

PALMERI, T. J., GOLDINGER, S. D., \& PISONI, D. B. (1993). Episodic encoding of voice attributes and recognition memory for spoken words. Journal of Experimental Psychology: Learning, Memory, and Cognition, 19, 309-328.

PATTERSON, D., \& CONNINE, C. M. (2001). Variant frequency in flap production: A corpus analysis of variant frequency in American English flap production. Phonetica, 58, $254-275$.

PETERS, R. W. (1955). The relative intelligibility of single-voice and multiple-voice messages under various conditions of noise. Joint Project Report, 56. U.S. Naval School of Aviation Medicine, Pensacola, Florida 1-9.

PILOTTI, M., \& BEYER, T. (2002). Perceptual and lexical components of auditory repetition priming in young and older adults. Memory \& Cognition, 30, 226-236.

PILOTTI, M., MEADE, M. L., \& GALLO, D. A. (2003). Implicit and explicit measures of memory for perceptual information in young adults, healthy older adults, and patients with Alzheimer's Disease. Experimental Aging Research, 29, 15-32.

PISONI, D. B. (1990). Effects of talker variability on speech perception: Implications for current research and theory. In H. Fujisaki (Ed.), Proceedings, of the 1990 International Conference on Spoken Language Processing, Kobe, Japan, November 18-22, 1990.

PISONI, D. B. (1992). Talker normalization in speech perception. In Y. Tohkura, E. VatikiotisBateson, \& Y. Sagisaka (Eds.), Speech perception, production, and linguistic structure. Ohmsha Press: Tokyo, Japan. 
PISONI, D. B. (1997). Some thoughts on "normalization" in speech perception. In K. Johnson \& J. W. Mullennix (Eds.), Talker variability in speech processing (pp.9-32). San Diego, CA: Academic Press.

REMEZ, R. E., FELLOWES, J., \& RUBIN, P. E. (1997). Talker identification based on phonetic information. Journal of Experimental Psychology: Human Perception and Performance, 23, $651-666$.

RYALLS, B. O., \& PISONI, D. B. (1997). The effect of talker variability on word recognition in preschool children. Developmental Psychology, 33, 441-452.

RYAN, C., CHASAIDE, A. N., \& GOBL, C. (2003). Voice quality variation and the perception of affect: Continuous or categorical? Proceedings of the International Congress of Phonetic Sciences, 2409-2412, Barcelona.

SALTHOUSE, T. A. (1985). A theory of cognitive aging. New York: Elsevier Science.

SCHACTER, D. L., \& CHURCH, B. A. (1992). Auditory priming: Implicit and explicit memory for words and voices. Journal of Experimental Psychology: Learning, Memory, and Cognition, 18, 915-930.

SCHACTER, D. L., CHURCH, B. A., \& OSOWIECKI, D. M. (1994). Auditory priming in elderly adults: Impairment of voice-specific implicit memory. Memory, 2, 295-323.

SOMMERS, M. S. (1996). The structural organization of the mental lexicon and its contribution to age-related declines in spoken-word recognition. Psychology and Aging, 11, 333-341.

SOMMERS, M. S. (1997). Stimulus variability and spoken word recognition II: The effects of age and hearing impairment. Journal of the Acoustical Society of America, 101, 2278-2288.

SOMMERS, M. S. (1998). Spoken word recognition in individuals with dementia of the Alzheimer's Type: Changes in talker normalization and lexical discrimination. Psychology and Aging, 13, $631-646$.

SOMMERS, M. S. (1999). Perceptual specificity and implicit auditory priming in older and younger adults. Journal of Experimental Psychology: Learning, Memory, and Cognition, 25, $1236-1255$.

Van LANCKER, D. R., KREIMAN, J., \& CUMMINGS, J. (1989). Voice perception deficits: Neuroanatomical correlates of phonagnosia. Journal of Clinical and Experimental Neuropsychology, 11, 665-674.

VITEVITCH, M. S., \& LUCE, P. A. (1998). When words compete: Levels of processing in perception of spoken words. Psychological Science, 9, 325-329.

VITEVITCH, M. S., \& LUCE, P. A. (1999). Probabilistic phonotactics and neighborhood activation in spoken word recognition. Journal of Memory and Language, 40, 374-408.

YONAN, C. A., \& SOMMERS, M. S. (2000). The effects of talker familiarity on spoken word identification in younger and older adults. Psychology and Aging, 15, 88-99. 